\title{
A Theory of Status Organizations
}

\author{
HENRY HANSMANN \\ Yale University
}

\section{INTRODUCTION}

There are many instances in which an individual's decision to patronize a firm depends not just upon the quality and price of the goods or services offered by the firm, but also upon the personal characteristics of the other patrons of the firm. Social clubs, such as country clubs, are conspicuous examples. The socioeconomic status and other personal attributes of a country club's membership are likely to be quite as important to a prospective member as are the quality of the golf course, the tennis courts, and the food served in the club diningroom. Private educational institutions provide another example: students commonly select a college not only on the basis of the quality of the instructional program, but also with an eye to the intelligence, earlier education, social attractiveness, athletic ability, and future promise of its other students.

Residential suburbs exhibit the same phenomenon. There, individuals have a strong incentive to patronize-that is, to reside in-a community composed of people who build expensive residences. This incentive derives not simply from a taste for attractive surroundings and affluent friends, but also from the fact that such neighbors raise the community's property tax base and thus reduce the effective price of municipal services.

Such considerations can be important not only in cases such as those just described, in which individuals are purchasing services from a firm, but also where individuals are selling services to a firm. A scholar, for example, will commonly choose employment with a particular university not just, or even

\footnotetext{
Preparation of this paper was supported by a grant from the Program on Non-profit Organizations, Institution for Social and Policy Studies, Yale University. I am particularly indebted to Alvin Klevorick, Richard R. Nelson, and Sidney Winter for helpful comments.
}

Journal of Law, Economics, and Organization vol. 2., no. 1 Spring 1986

(c) 1986 by Yale University. All rights reserved. ISSN 8756-6222 
primarily, on the basis of work conditions such as salary and teaching load, but also on the basis of the professional accomplishments of the other members of the faculty. Similarly, a lawyer will typically seek to sell his services to a law firm in which the other lawyers are as competent as possible. In this case, as with suburbs, the motivation is in part directly pecuniary: since income within law firms is generally pooled to some extent, each lawyer's income is dependent upon the productivity of his colleagues.

In the discussion that follows, the term status will be used to refer to the degree to which an individual exhibits those attributes that make him desirable as a fellow patron in an organization such as those described above (and patron will be used here to refer to a seller to, as well as a purchaser from, a firm). For example, among law firms one's status is determined by one's intelligence, skills, and industry-in short, by one's earning power as a lawyer. Among suburbs, one's status is determined by the value of the residence one is prepared to occupy. We are concerned here, then, with firms in which the attraction of patronage depends, at least in part, upon the status of the other members. For convenience, such firms will be referred to here in general as "status organizations."

Status organizations of all types are commonly characterized by three distinctive features. First, they are typically exclusive in the sense that each organization establishes a minimum status level for patronage, a requirement that is imposed in addition to the price that is paid to or by the firm. Thus, country clubs regularly establish (explicit or implicit) membership criteria in terms of socioeconomic status; colleges establish minimum academic requirements for admission; and suburbs require that their residents be prepared to occupy a lot of at least a given number of acres and build a house that conforms to certain minimal standards.

Second, patrons tend to be stratified among status organizations in terms of their status. That is, the highest-status individuals typically patronize one organization, while the people in the next status range patronize a second organization, and so forth. Thus Eastern colleges, Wall Street law firms, Chicago suburbs, or Philadelphia Main Line country clubs can be assigned a rough ranking according to the status of their respective members. Seldom does a single organization have patrons who represent a broad range of status levels.

Finally, and of most interest as an issue of economic organization, status organizations are commonly organized and operated on a cooperative basis. That is, rather than being owned and operated by profit-seeking entrepreneurs, they are controlled by their patrons, either through direct ownership (as in a law partnership) or through a nonprofit corporation (as in a country club or college) $)^{l}$ or a municipal corporation (as in a suburb) that is patron-controlled.

1. The board of trustees of a private college or university is typically elected (to the extent they are elected at all) by the school's graduates rather than by its current students. But then, 
The class of status organizations that exhibit these three characteristics of exclusivity, stratification, and cooperative control is extremely broad. For instance, in addition to the examples already mentioned, this class arguably includes upper-income cooperative apartment buildings, mutual insurance companies (Hansmann, 1985a: 147), the medical staffs of metropolitan hospitals, and marriages.

Exclusivity, stratification, and cooperative control apparently arise largely in response to externalities deriving from the varying status levels of potential members. If an organization were willing to accept any individual as a patron, regardless of his status, at a given uniform price, then each patron's status level would have the character of an externality with respect to other patrons of the firm; by patronizing a given firm a high-status individual would cast an external benefit upon the other patrons, while a low-status individual would give rise to an external disbenefit by becoming a patron.

To some extent such potential externalities can be, and are, internalized by making the prices that are charged or paid patrons a function of each individual's personal status. But more commonly than not the correlation between the price for patronage and a patron's individual status is imperfect or completely nonexistent. Social clubs, for example, generally charge the same dues to all members. Among educational institutions, merit scholarships are the exception and not the rule. And even among law firms and other professional partnerships the division of income is generally no more than roughly proportional to an individual's actual contribution to the prosperity of the firm; indeed, some of the nation's most prominent and prosperous law firms apportion earnings among partners simply according to length of tenure with the firm (Gilson and Mnookin).

One likely reason for this relative absence of discrimination in prices is that the feelings of camaraderie among patrons would be severely harmed by a system of charges that gives formal recognition to invidious distinctions (see Frank, 1983; 1984). Another reason may be that, among patrons of any given firm, it is difficult to draw distinctions of sufficient refinement to support a system of differentiated fees. Legal constraints sometimes also play a role; suburban municipalities, for example, generally lack the authority to set up a highly differentiated system of fees or taxes (Heyman and Gilhool). And risk-sharing has been offered as an explanation for the egalitarian division of earnings often seen in partnerships of professionals (Gilson and Mnookin).

Whatever the reason, the externality problem remains a real one for most status organizations. And it appears that exclusivity, stratification, and cooperative control are largely responses to it. The nature of this relationship, and its consequences for the formation and behavior of systems of status organizations, is the subject of the remainder of this essay. ${ }^{2}$

perhaps the most important club one is ultimately joining by going to, say, Yale is the club of Yale graduates.

2. See Schelling (197la, 1971b, undated) and Gale and Shapley for somewhat different treatments of sorting phenomena in interpersonal association. 
Because the social club is the prototypical example of a status organization, such firms will generally be referred to here simply as "clubs," and their patrons as "members." The use of the term club here, however, should not be taken to suggest more than a tangential relationship between this essay and the "economic theory of clubs" literature (see Sandler and Tschirhart), which has confined its attention largely to the economics of collective consumption goods and has generally neglected the status phenomena that are the principal focus here. ${ }^{3}$

\section{A SIMPLE MODEL}

The essential incentives at work in status organizations can be illustrated with a simple model.

Assume that individuals in society can be represented by points on the continuum $[O, N]$. Each individual $m \varepsilon[O, N]$ has a status level $s(m)$ that is fixed and beyond his control. An individual's status can be immediately and costlessly recognized by any other individual. No two individuals have precisely the same status. Individuals are ordered in terms of their status, so that $s(k)>s(m)$ for $k<m$.

Individuals join clubs exclusively for the purpose of associating with other individuals. The utility that an individual derives from membership in a given club depends upon only two factors: (1) the average status of the club's membership (including the individual in question), and (2) the membership fee that the individual is charged by the club. Holding these two factors constant, the individual is indifferent to the size of the club. Individuals can (or choose to) belong to only one club at a time.

All individuals have the same monetary income, $y$, and the same utility function. In particular, the utility enjoyed by an individual $m$ who belongs to a club $j$ that charges him a membership fee $f_{m}^{j}$ and whose members have an average status $\bar{s}^{j}$, is given by $U_{m}^{j}=U\left(y-f_{m}^{j}, \bar{s}^{j}\right)$, where $\partial U / \partial y>0$, $\partial U / \partial \bar{s}>0, \partial^{2} U / \partial y^{2} \leqslant 0$, and $\partial^{2} U / \partial \bar{s}^{2} \leqslant 0$. (Throughout, subscripts will refer to individuals and superscripts will refer to clubs.) Note that this assumes that a person's utility function does not depend directly upon his own status.

The cost of operating a club is a function only of the size of its membership. In particular, the average cost-that is, the cost per member-of operating a given club $j$ with membership size $n^{j}$ is given by $C\left(n^{j}\right)$, where $C^{\prime}\left(n^{j}\right) \lesseqgtr 0$ as $n^{j} \lesseqgtr n^{*}$, and $C^{\prime \prime}\left(n^{j}\right)>0$ everywhere. Thus there are limited economies of scale in operating a club, with $n=n^{*}$ being the club size at which cost per member is minimized.

An individual's own status can affect his utility only if he belongs to a club (where, as noted above, the individual's own status level is included in

3. One exception is DeSerpa, who notes that preferences among club members concerning the personal characteristics of other members might create incentives for pricing or exclusion based on such characteristics. See also Tollison. 
determining the average status level of the club). An individual who does not belong to a club has utility $U=U_{\text {min }}$, where $U_{\min }$ is the same for all individuals and is thus independent of the individual's own status.

Finally, we shall assume that, for reasons such as those discussed in section 1 , a given club is constrained to charge all of its members the same membership fee, regardless of their status.

\section{COOPERATIVE CLUBS}

Consider now a system of clubs organized as cooperatives. All members of a club $j$ that charges a (uniform) fee $f^{j}$ will experience the same level of utility, $U^{j}=U\left(y-f^{j}, \bar{s}^{j}\right)$, regardless of their personal status. Thus, in this simple model, all members of such a club will be in unanimity concerning the desirability of any action to be taken by the club. ${ }^{4}$ The members of a cooperative club can be assumed to choose to set its membership fee equal to its average cost, $f^{j}=C\left(n^{j}\right)$, since they have no incentive to operate the club at either a profit or a loss..$^{5}$

Assume for the moment that club formation is costless. Then it is natural to define an equilibrium system of cooperative clubs as one in which no collection of individuals has an incentive to leave their current clubs and regroup themselves into a new club. More precisely, a system of cooperative clubs $\Phi$ will be said to constitute an equilibrium if there exists no feasible non-empty club $\alpha$ such that (a) all individuals in club $\alpha$ would be at least as well off in club $\alpha$ as they are in system $\Phi$, and (b) at least one member of club $\alpha$ would be better off in club $\alpha$ than under system $\Phi$. (By "feasible" we mean here that a club's fees are sufficient to cover its costs.)

We can then establish the following four propositions: (I) A cooperativeclub equilibrium exists for any status distribution; (II) such an equilibrium system is strictly stratified, where by "strictly stratified" we mean that, for any two clubs $i$ and $j$ in the system, either (a) $s(m) \geqslant s(k)$ for all individuals $m$ in club $i$ and all individuals $k$ in club $j$, or (b) $s(m) \leqslant s(k)$ for all individuals $m$ in club $i$ and all individuals $k$ in club $j$; (III) $U^{i}>U^{j}$ for two clubs $i$ and $j$ in

4. There is one exception to this: a member might differ with the other members concerning the desirability of his own expulsion. Assuming that the member or members to be expelled are in the minority, we need only assume that in those cases the wishes of the majority prevail.

5. The model applies to law firms and other producer cooperatives by giving the utility function the particular form

$$
U^{i}=U\left[y-C\left(n^{i}\right), \bar{s}^{i}\right]=G\left[y-\left(n^{i}\right)+\bar{s}^{i}\right]
$$

where $G^{\prime}>0, G^{\prime \prime}<0, s$ is the income produced by a given partner, $y$ is the partner's income from sources outside the firm (here presumed equal for all-it can be set at zero for simplicity), and $C(n)$ is the average business expense incurred by a firm with $n$ partners. For detailed interpretations of the model as it applies to residential suburbs and insurance companies, see Hansmann (1985b). 
an equilibrium system if club $i$ is of higher status than club $j ;$ (IV) the equilibrium system is unique.

To prove proposition I it suffices to construct a system of clubs, labeled system $\hat{\Phi}$, as follows.

Form the first club, "club 1," by drawing from the individuals at the top of the status ordering, starting with individual 0 . The average status $\bar{s}^{1}$ of this club will be a function of its size, $n^{1}$. Choose that value for $n^{1}$ that maximizes the utility of the club's members, $U^{1}=U\left[y-C\left(n^{1}\right), \bar{s}^{1}\right]$. If there are two or more values of $n^{1}$ that yield the same maximal value for $U^{1}$, choose the largest. Denote this membership size for club 1 by $n^{1}$ (equilibrium values of variables for a system of cooperative clubs will be denoted by "^").

Now form club 2 in a similar manner from the highest-status individuals among the remaining $N-\hat{n}^{1}$ individuals not in club 1 . Denote the size of club 2 by $\hat{n}^{2}$. Continue this process for club 3, etc., until either (a) all $N$ individuals belong to one or another club, or (b) there exist $\hat{n}^{\mathrm{u}}$ individuals at the bottom of the status ordering who do not belong to a club, but who are so few in number or so low in status that no feasible club offers any subset of these individuals greater utility than $U_{\min }$. It is obvious that, for all $i, \hat{n}^{i}<n^{*}$ (the size that minimizes cost per member); the savings in cost per member involved in expanding club size toward $n^{*}$ will, beyond some point, be outweighed in the members' eyes by the decline in the club's status that such expansion of membership entails.

The resulting system of clubs $\hat{\Phi}$, which clearly is strictly stratified, constitutes an equilibrium. For suppose there exists a non-empty club, club $\alpha$, with membership size $n^{\alpha}$ and average status $\bar{s}^{\alpha}$, that is not in system $\hat{\Phi}$ and that would offer at least one of its members a utility level higher than that which they would enjoy under system $\hat{\Phi}$ and would make none of its members worse off. Such a club $\alpha$ cannot include any of the $n^{1}$ members of club 1 . For, by definition of $n^{1}$,

$$
\begin{aligned}
& U^{1}= U\left[y-C\left(n^{1}\right), \bar{s}^{1}\right] \geqslant U\left[y-C\left(n^{\alpha}\right), \tilde{s}\right] \geqslant \\
& U\left[y-C\left(n^{\alpha}\right), \bar{s}^{\alpha}\right]=U^{\alpha}
\end{aligned}
$$

where $\tilde{s}$ is the average status of the $n^{\alpha}$ highest-status individuals in society. And if club $\alpha$ is to contain any of the members of club 1, then (1) must hold with equality (since otherwise those members would be worse off in club $\alpha$ than in club 1). But, since no two individuals are of the same status, we can have $U\left[y-C\left(n^{\alpha}\right), \tilde{s}\right]=U\left[y-C\left(n^{\alpha}\right), \bar{s}^{\alpha}\right]$ only if the members of club $\alpha$ comprise the $n^{\alpha}$ highest-status individuals in society. From the definition of $\hat{n}^{\mathbf{1}}$, the membership of club $\alpha$ must then constitute a subset of the membership of club 1 . Therefore, by virtue of (1), no member of club $\alpha$ can be better off in club $\alpha$ than under system $\hat{\Phi}$, contradicting the definition of club $\alpha$.

By similar reasoning, if club $\alpha$ does not include any of the members of club 1 , then it cannot include any of the members of club 2 . And, by continued 
extension of this logic, club $\alpha$ must in fact include among its members none of the individuals who belong to clubs in system $\hat{\Phi}$. Nor can the membership of club $\alpha$ consist of any subset of the $\hat{n}^{u}$ individuals who do not belong to clubs in system $\hat{\Phi}$, by virtue of the defining characteristic of that group. Thus club $\alpha$ must be empty, contradicting its definition.

To prove Proposition II, consider a system of clubs $\Theta$ that is not strictly stratified. This system must contain two clubs $i$ and $j$ such that, for some individuals $m$ and $k$ in club $i$ and some individuals $u$ and $v$ in club $j, s(m)>$ $s(u)$ and $s(k)<s(v)$. Clearly either $U^{i} \geqslant U^{j}$ or $U^{j} \geqslant U^{i}$; assume the former, without loss of generality. Now consider a club $i^{\prime}$ that is identical to club $i$ except that it contains individual $v$ as a member and does not contain individual $k$. Then $U^{i \prime}>U^{i} \geqslant U^{j}$, and hence all individuals in club $i^{\prime}$ are better off in club $i^{\prime}$ than under system $\Theta$. Therefore system $\Theta$ does not constitute an equilibrium. Consequently, any system of clubs that is an equilibrium must be strictly stratified.

Proofs of Propositions III and IV are straightforward and are omitted.

The exclusivity of the clubs in the resulting equilibrium is clearly reflected in the fact that, although each individual would prefer to be a member of any club of higher status than the one he is in, he will be refused admission on account of his status.

Note that the hierarchical ranking of clubs that characterizes the equilibrium system is quite stable, in that there is no simple incremental process by which a club can improve its position in the hierarchy. Because, in general, each club in the equilibrium system offers a utility level that is substantially lower than that offered by the club just above it in the hierarchy, it is in a poor position to compete with such a club (or any other higher-status club) for high-status members. Moreover, the addition of just one member of unusually high status will typically have only a small effect on the average status of a club and will not improve substantially its ability to compete for other highstatus individuals; a club will be able to move up the hierarchy only by a wholesale substitution of new, high-status members for its old membership, and this is likely to be difficult to accomplish, particularly if the membership of the club turns over only gradually, causing substantial overlap between new and old generations of members. This may be one reason why the pecking order among many types of status organizations, including country clubs, elite colleges, residential suburbs, and prestigious law firms, is remarkably constant over time. ${ }^{6}$

6. For simplicity, we have assumed here that all individuals are of different status. This assumption is not, however, especially important. In particular, Proposition II (which states that any equilibrium system will be strictly stratified) holds for any status distribution. The principal complication introduced by permitting more than one individual in society to have the same status is simply that in some cases there may be multiple equilibria. (See Hansmann, 1985b, for formal analysis.) 


\section{PROPRIETARY CLUBS}

It is not surprising that, as just illustrated, status organizations have incentives for exclusivity and stratification. It is less obvious why such firms are so commonly organized as cooperatives. Certainly cooperative control is unnecessary for exclusivity; at least until the Civil Rights Act of 1964, there was no obvious legal or practical obstacle to prevent a proprietary club from setting any standards it chose for membership, and there are examples of proprietary clubs that have been quite exclusive. ${ }^{7}$ Moreover, the services provided by most clubs are not characterized by the problems of asymmetric information or contract failure that seem to explain the presence of nonproprietary firms in many other industries (Hansmann, 1980).

Rather, status organizations are evidently formed as cooperatives in large part to protect their members from the monopolistic exploitation to which they would otherwise be subject. To see this, it is instructive to compare the cooperative-club equilibrium just described with that which would result if clubs were owned and operated by profit-maximizing entrepreneurs.

\subsection{With Concerted Behavior among Members}

Consider first the case in which all clubs are proprietary, club formation is costless, and individuals can form coalitions costlessly among themselves for the sake of dealing with club owners. In this case we would expect an equilibrium system of proprietary clubs to be the same as that described in section 3 for cooperative clubs, namely $\hat{\Phi}$. The $\hat{n}^{1}$ highest-status individuals will have an incentive to form a coalition to bargain with entrepreneurs for a club confined to them only, with fees equal to costs, and competition among entrepreneurs will assure that they get it-and so on for the other coalitions that characterize system $\hat{\Phi}$. In short, the results of section 3 are not significantly altered by merely interposing entrepreneurs as the agents of club formation.

The clubs in such a system are, in fact, cooperatively controlled. The members, acting in concert, are effectively hiring the management through a system of competitive bidding. And if the members are sufficiently well organized to undertake such collective bargaining, it seems natural to expect them to take the final step of establishing formal ownership of the club and thus avoid the difficulties of negotiating repeatedly in the future with an independent management. (See Williamson on "unified governance.")

The important issue, therefore, is the strength of the incentive for forming coalitions among club members. That is, how much worse off would the individual club members be if they did not cooperate in exercising control over their clubs?

7. For example, even at the peak of their popularity, many leading English men's clubs, though highly exclusive, were proprietary (Chafee: 1000). 


\subsection{Without CONCERTED BEHAVIOR AMONG MEMBERS}

If the members of a proprietary club do not act cooperatively but instead contract with the owner of the club on their own, independently of the other club members, then the owner of the club will be in a position to extract pure profits from them and leave the members substantially worse off than they would be in a cooperatively controlled club.

To see this, it suffices to consider the behavior of a single proprietary club operating in an environment otherwise composed exclusively of cooperative clubs. To this end, begin by considering the cooperative club equilibrium, system $\hat{\boldsymbol{\Phi}}$, described in section 3 . Now assume that one club-which we shall assume, without loss of generality, is the highest-status club in the system, club 1 -is acquired by a profit-maximizing owner who has the authority to alter the club's price and membership requirements at will (subject to the necessity to attract and retain members and to cover costs) and who adjusts these variables to maximize the club's profits. The rest of the clubs in the system, meanwhile, remain cooperatives and behave as such, setting price equal to cost and choosing the membership size (that is, the level of exclusivity) that maximizes utility for the members.

Finally, assume that both present and prospective members of club 1 contract with the owner of that club as individuals, not collectively. To capture this notion formally, assume that an individual will prefer to be a member of club 1 rather than another club, club $j$, if and only if, given the current membership and fees of those clubs, $U^{1} \geqslant U^{j}$.

It is natural here to define a (Nash) equilibrium as a system of fees and of allocations of members to clubs such that (a) given the behavior of the other clubs in the system, no club wishes to change its membership requirements or fee, and (b) given the current membership and fees of the various clubs, no individual wishes to join a club of which he is currently not a member and that is willing to admit him to membership.

We can then prove the following two Propositions concerning club 1 when it is operated as a proprietary firm in equilibrium: (V) club 1 will set price above cost and thus extract pure profits from its members; (VI) if status is a normal good, club 1 will have a larger (and thus less exclusive) membership size than its members would choose if it were a cooperative.

To establish Proposition V, note that the owner of club 1 can, while keeping the same $\hat{n}^{1}$ members as in the cooperative club equilibrium $\hat{\Phi}$, raise the membership fee to $P^{*}$, where $P^{*}$ is such that $U^{1}=U\left(y-P^{*}, \bar{s}^{1}\left(\hat{n}^{1}\right)\right)=\hat{U}^{2}$. Since $\hat{U}^{1}<\hat{U}^{2}$ by Proposition III, $U^{1}=U\left(y-P^{*}, \bar{s}^{1}\left(\hat{n}^{1}\right)\right)<\hat{U}^{1}$, and hence $P^{*}>C\left(n^{1}\right)$. The resulting profit $\Pi^{1}=n^{1}\left[P^{*}-C\left(\hbar^{1}\right)\right]>0$ is thus a lower bound on the profits the owner of club 1 can realize.

The resulting fee and membership size for club $1,\left(P^{*}, n^{1}\right)$, however, in general will not be an equilibrium allocation. As Proposition VI suggests, so long as club status is a normal good (and the second-order condition for a profit maximum is satisfied throughout the relevant range), club 1 can increase its 
profits further by "raiding" high-status members from club 2-that is, by lowering its price marginally below $P^{*}$ (so that $U^{1}>U^{2}$ ) and lowering its admission requirements, thereby expanding the club's size by attracting to it the highest-status members of club 2 . Corresponding adjustments in membership will then be induced in clubs 2,3, and so on. (For formal analysis and proof of Proposition VI, see Hansmann, 1985b).

Note that the proprietary club is able to earn pure profits here even though all the other clubs with which it competes are setting price equal to cost. Such profits can be maintained because the competing clubs are not offering a homogeneous product. Rather, the product being sold-the opportunity to associate with people of a given status-is highly differentiated. The higheststatus club has a degree of monopoly power that derives from the fact that there is a scarcity of high-status individuals in society, so that no other club can offer a membership of comparably high status.

\subsection{InCEnTIVES FOR Forming CoOperatives}

It follows that the members of club 1 are better off when it is operated as a cooperative than when it is operated as a proprietary firm. By acting collectively, the members can avoid the monopolistic exploitation to which they would be subject if they were to deal as individuals with a proprietary club. This is entirely in keeping with the role that cooperatives play in other sectors of the economy; both consumer and producer cooperatives frequently arise where their patrons would otherwise face a monopolist or a monopsonist (Hansmann, 1980; 889-90; 1985a; Heflebower). The novel element in the case of status organizations is that the thing that a proprietary firm is selling to its patrons at a monopoly price is the patrons' own high status-which undoubtedly makes such an arrangement particularly galling to the patrons. ${ }^{8}$

As in other situations where cooperatives provide an alternative to monopolistic exploitation, the costs of organizing the patrons evidently constitute a crucial factor. We would expect the cooperative form to arise only where such costs are low relative to the benefits to be obtained from avoidance of exploitation. The members of a country club, for example, are relatively easy to organize, since the members generally live near each other, the club occupies a substantial part of the members' time and finances, and the membership changes only slowly over time.

8. Klein et al. (322-23) have pointed to another reason why social clubs and similar organizations might be owned by their members. Whatever their initial motives for joining, over time the members of a club may form personal bonds among themselves that would be painful to give up. The owner of a proprietary club could, therefore, increase membership fees over time to capture, as rents, the value to the members of retaining these bonds. Ownership by members avoids this. 


\section{CONCLUSION}

Even among the particular types of organizations invoked here as examples-including social clubs, schools, and law firms-exclusivity, stratification, and cooperation are not entirely attributable just to the externalities deriving from the status phenomena explored above. Undoubtedly schools are exclusive and stratified at least in part because there are economies involved in educating students who are all of roughly similar abilities and background. ${ }^{9}$ Presumably social clubs are sometimes run as cooperatives simply because the management of the club is a consumption good for the members. And law firms are organized as lawyers' cooperatives at least in part because of monitoring and incentive problems (Jensen and Meckling) and because it is illegal in every state to organize them in any other way (Hansmann, 1981: 543-45).

Moreover, incentives for exclusivity, stratification, and cooperation may be weakened if some of the model's simplifying assumptions are relaxed. In particular, stratification among status organizations is likely to become blurred to a greater or lesser degree where individuals differ in their preferences or income, and especially if such differences are uncorrelated with individuals' personal status.

Nevertheless, wherever the personal characteristics of one's fellow consumers or workers are an important source of utility and cannot effectively be dealt with by intraorganizational variations in price, incentives for exclusivity, stratification, and cooperative control will be present. And these incentives help to explain the structure and behavior of many otherwise dissimilar types of institutions.

9. Further, status externalities are sufficient but not necessary for the development of stratification in systems of status organizations such as those modeled in section 3; there can sometimes be incentives for stratification even where membership fees can be adjusted to each individual's status (Hansmann, 1985b).

\section{REFERENCES}

Chafee, Zechariah. 1930. "The Internal Affairs of Associations Not for Profit," 43 Harvard Law Review 993-1029.

DeSerpa, A. C. 1977. "A Theory of Discriminatory Clubs," 24 Scottish Journal of Political Economy 33-41.

Frank, Robert H. 1983. "Interdependent Preferences, Coase, and the Competitive Wage Structure," working paper no. 19, Center for the Study of American Political Economy, Cornell University.

_ 1984. "Are Workers Paid Their Marginal Products?" 74 American Economic Review 549-71.

Gale, David, and L. S. Shapley. 1962. "College Admissions and the Stability of Marriage," 69 American Mathematical Monthly 9-15.

Gilson, Ronald, and Robert Mnookin. 1985. "Sharing among the Human Capitalists: 
An Economic Inquiry into the Corporate Law Firm and How Partners Split Profits," 37 Stanford Law Review 313-92.

Hansmann, Henry B. 1980. "The Role of Nonprofit Enterprise," 89 Yale Law Journal $835-901$.

_. 1981. "Reforming Nonprofit Corporation Law," 129 University of Pennsylvania Law Review 497-623.

_. 1985a. "The Organization of Insurance Companies: Mutual versus Stock," 1 Journal of Law, Economics, and Organization 125-53.

. 1985b. "Externalities, Exclusivity, Stratification, and Cooperation: A Theory of Associative Organizations," working paper no. 2, Program on Non-Profit Organizations, Institution for Social and Policy Studies, Yale University.

Heflebower, Richard B. 1980. Cooperatives and Mutuals in the Market System. Madison: University of Wisconsin Press.

Heyman, Michael I., and T. K. Gilhool. 1964. "The Constitutionality of Imposing Increased Community Costs on New Suburban Residents through Subdivision Exactions," 73 Yale Law Journal 1119-57.

Jensen, Michael, and William Meckling. 1979. "Rights and Production Functions: An Application to Labor-Managed Firms and Codetermination," 52 Journal of Business 469-506.

Klein, Benjamin; Robert Crawford; and Armen Alchian. 1978. "Vertical Integration, Appropriable Rents, and the Competitive Contracting Process," 21 Journal of Law and Economics 297-326.

Sandler, T., and J. T. Tschirhart. 1980. "The Economic Theory of Clubs: An Evaluative Survey," 18 Journal of Economic Literature 1481-1521.

Schelling, Thomas C. 1971. "Dynamic Models of Segregation," 1 Journal of Mathematical Sociology 143-86.

-1 1971. "On the Ecology of Micromotives," 25 Public Interest 61-98.

—_. "Segregation on a Continuous Variable." Unpublished, undated.

Tollison, R. D. 1972. "Consumption Sharing and Non-Exclusion Rules," 39 Economica 276-91.

Williamson, Oliver. 1979. "Transaction Cost Economics: The Governance of Contractual Relations," 22 Journal of Law and Economics 233-61. 